\title{
COVID-19 pneumonia: pathophysiology and management
}

\author{
Luciano Gattinoni $\mathbb{1}^{1}$, Simone Gattarello ${ }^{1}$, Irene Steinberg ${ }^{1}$, Mattia Busana $\mathbb{1}^{1}$, Paola Palermo ${ }^{1}$, \\ Stefano Lazzari ${ }^{1}$, Federica Romitti ${ }^{1}$, Michael Quintel ${ }^{1,2}$, Konrad Meissner ${ }^{1}$, John J. Marini ${ }^{3}$, \\ Davide Chiumello ${ }^{4}$ and Luigi Camporota ${ }^{5}$
}

\begin{abstract}
${ }^{1}$ Dept of Anesthesiology, University Medical Center Göttingen, Göttingen, Germany. ${ }^{2}$ Dept of Anesthesiology, Intensive Care and Emergency Medicine Donau-Isar-Klinikum Deggendorf, Deggendorf, Germany. ${ }^{3}$ Dept of Pulmonary and Critical Care Medicine, University of Minnesota and Regions Hospital, St. Paul, MN, USA. ${ }^{4}$ Dept of Anesthesia and Intensive Care, San Paolo Hospital, University of Milan, Milan, Italy. ${ }^{5}$ Dept of Adult Critical Care, Guy's and St Thomas' NHS Foundation Trust, Health Centre for Human and Applied Physiological Sciences, London, UK.
\end{abstract}

Corresponding author: Luciano Gattinoni (gattinoniluciano@gmail.com)

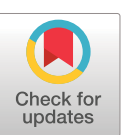

Copyright OThe authors 202

This version is distributed under the terms of the Creative Commons Attribution Non-Commercial Licence 4.0. For commercial reproduction rights and permissions contact permissions@ersnet.org

Received: 18 June 2021 Accepted: 8 Aug 2021

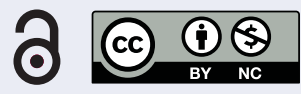

Shareable abstract (@ERSpublications)

COVID-19 pneumonia cannot be correctly described, analysed and treated if the time-factor is not taken into account https://bit.ly/3AOKxc4

Cite this article as: Gattinoni L, Gattarello S, Steinberg I, et al. COVID-19 pneumonia: pathophysiology and management. Eur Respir Rev 2021; 30: 210138 [DOI: 10.1183/16000617.0138-2021].

\section{Abstract}

Coronavirus disease 2019 (COVID-19) pneumonia is an evolving disease. We will focus on the development of its pathophysiologic characteristics over time, and how these time-related changes determine modifications in treatment. In the emergency department: the peculiar characteristic is the coexistence, in a significant fraction of patients, of severe hypoxaemia, near-normal lung computed tomography imaging, lung gas volume and respiratory mechanics. Despite high respiratory drive, dyspnoea and respiratory rate are often normal. The underlying mechanism is primarily altered lung perfusion. The anatomical prerequisites for PEEP (positive end-expiratory pressure) to work (lung oedema, atelectasis, and therefore recruitability) are lacking. In the high-dependency unit: the disease starts to worsen either because of its natural evolution or additional patient self-inflicted lung injury (P-SILI). Oedema and atelectasis may develop, increasing recruitability. Noninvasive supports are indicated if they result in a reversal of hypoxaemia and a decreased inspiratory effort. Otherwise, mechanical ventilation should be considered to avert P-SILI. In the intensive care unit: the primary characteristic of the advance of unresolved COVID-19 disease is a progressive shift from oedema or atelectasis to less reversible structural lung alterations to lung fibrosis. These later characteristics are associated with notable impairment of respiratory mechanics, increased arterial carbon dioxide tension $\left(\mathrm{P}_{\mathrm{aCO}}\right)$, decreased recruitability and lack of response to PEEP and prone positioning.

\section{Introduction}

Coronavirus disease 2019 (COVID-19) is an ongoing pandemic caused by the novel severe acute respiratory syndrome coronavirus 2 (SARS-CoV-2), first isolated in December 2019 in Wuhan, China [1]. Since then, more than 160 million infected cases have been reported worldwide, with a death toll of almost 3.5 million individuals [2]. The clinical features of COVID-19 are highly variable, ranging from asymptomatic patients to severe forms of respiratory failure, and may change remarkably with time. Better understanding of the pathophysiology of COVID-19, achieved over a short time, has led to a significant improvement in medical treatment and outcomes for a large proportion of patients [3]. It is however a significant concern that the mortality among the most severely ill patients remains unacceptably high [4].

The approach we take with this review starts with the analysis and interpretation of the disease trajectory which we divided conceptually into five phases based on the intensity of treatment required and the location where the treatment should ideally take place: out-of-hospital, emergency department, high-dependency unit (HDU), intensive care unit (ICU) and post-discharge environment (figure 1).

We focus on the time-related pathophysiological characteristics and the concomitant respiratory treatment that generally occurs between hospital admission and discharge from the ICU. For each phase we 


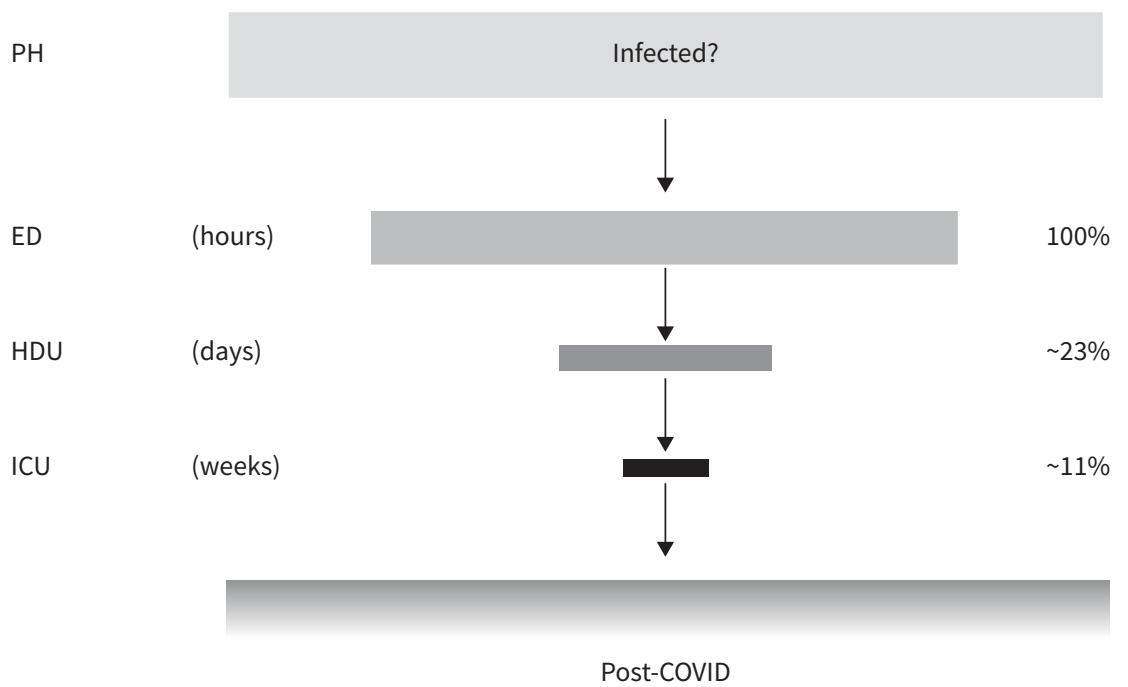

FIGURE 1 A representative flow of patients with COVID-19 from the emergency department through the high-dependency unit to intensive care from an unspecified number of infected individuals. Data from MARTINELLI et al. [5], from 281461 patients. Post-COVID-19 data not available. ED: emergency department; HDU: high-dependency unit; ICU: intensive care unit; $\mathrm{PH}$ : prehospital.

summarise the current understanding of COVID-19 pathophysiology and provide interpretative keys relevant for the clinical management of this large group of patients.

It is worth underlining, however, that the progression of COVID-19 disease may resolve at any of the stages we will describe for reasons which are currently not fully understood.

\section{In the emergency department}

Patients with COVID-19 infection present to the emergency department with a range of clinical symptoms. The peculiar feature, however, is the unique relationship between gas exchange, respiratory mechanics and imaging.

\section{Clinical presentation}

The most common presenting symptoms described in the literature in the first and second European waves of the pandemic are dry cough, fever and conjunctivitis; followed by symptoms affecting the gastrointestinal system such as nausea and diarrhoea [6-22] (table 1). Peculiar to COVID-19 is the frequent complaint of anosmia and ageusia, reflecting viral entry into the neurological system via the olfactory nerve [23]. This initial clinical presentation was similar in the two pandemic waves.

\section{Gas exchange}

The $P_{\mathrm{aO}_{2}} / F_{\mathrm{IO}_{2}}$ (arterial partial pressure of oxygen/inspiratory oxygen fraction) ratio at presentation varies widely from values more than $300 \mathrm{mmHg}$ to values as low as $50 \mathrm{mmHg}$ [24], while the values of $P_{\mathrm{aCO}_{2}}$ (partial pressure of carbon dioxide) spans a narrower range (typically 30-40 mmHg) [25]. Despite these abnormalities of gas exchange, the respiratory rate is often normal or only modestly increased [24, 25]. A frequent characteristic of COVID-19 pneumonia is the dissociation between the severity of the hypoxaemia and the comparative low prevalence of dyspnoea [24], a condition designated as "silent hypoxaemia” by early scientific literature and popularised by the communication media [26].

\section{Imaging}

In the first few days, the incidence of normal chest computed tomography (CT) findings in symptomatic patients with COVID-19 can be between $10 \%$ and $30 \%$ of cases. This incidence may reflect the degree of inflammatory response mounted by individual patients in response to the viral infection. In the emergency department, the typical radiological appearance of COVID-19 pneumonia is a radiograph showing bilateral patchy infiltrates, while the CT characteristically shows ground-glass infiltrates, primarily in the posterior and peripheral regions of the lungs (figure 2a) [27, 28]. 


\begin{tabular}{|c|c|c|c|c|}
\hline Variables & First wave & Second wave & Wave & References \\
\hline \multirow[t]{2}{*}{ Age (years) } & $61 \pm 11.63$ & $52 \pm 18.6$ & $1^{\circ}$ & {$[6,7,9,12,14,16,17,19-22]$} \\
\hline & & & $2^{\circ}$ & {$[14,15,17,19-22]$} \\
\hline \multirow[t]{2}{*}{ Gender, male (\%) } & 51 & 55 & $1^{\circ}$ & {$[6-9,14-17,19-22]$} \\
\hline & & & $2^{\circ}$ & {$[14,15,17,19-22]$} \\
\hline \multicolumn{5}{|l|}{ Symptoms] } \\
\hline \multirow[t]{2}{*}{ Cough (\%) } & 47.2 & 40.8 & $1^{\circ}$ & {$[6,8,13,14,16,19,22]$} \\
\hline & & & $2^{\circ}$ & {$[13,14,19,22]$} \\
\hline \multirow[t]{2}{*}{ Fever (\%) } & 46.6 & 55 & $1^{\circ}$ & {$[6,8,14,16,19,22]$} \\
\hline & & & $2^{\circ}$ & {$[13,14,19,21,22]$} \\
\hline \multirow[t]{2}{*}{ Dyspnoea (\%) } & 31.7 & 33.5 & $1^{\circ}$ & {$[6,8,13,14,16,19,22]$} \\
\hline & & & $2^{\circ}$ & {$[13,14,19,22]$} \\
\hline \multirow[t]{2}{*}{ Fatigue, asthenia (\%) } & 18.2 & 27 & $1^{\circ}$ & {$[8,16]$} \\
\hline & & & $2^{\circ}$ & {$[22]$} \\
\hline \multirow[t]{2}{*}{ Acute kidney injury (\%) } & 10.8 & 17 & $1^{\circ}$ & [19] \\
\hline & & & $2^{\circ}$ & [19] \\
\hline \multirow[t]{2}{*}{ Diarrhoea (\%) } & 6 & 5 & $1^{\circ}$ & {$[6,8,14,16,19]$} \\
\hline & & & $2^{\circ}$ & {$[13,14,19,22]$} \\
\hline \multirow[t]{2}{*}{ Vomiting (\%) } & 2.7 & 5 & $1^{\circ}$ & {$[14,16,19]$} \\
\hline & & & $2^{\circ}$ & {$[14,19]$} \\
\hline \multirow[t]{2}{*}{ Neurological symptoms (\%) } & 0.6 & 0.7 & $1^{\circ}$ & {$[14,16]$} \\
\hline & & & $2^{\circ}$ & [14] \\
\hline \multicolumn{5}{|l|}{ Gas exchange] } \\
\hline \multirow[t]{2}{*}{$P_{\mathrm{aO}_{2}}(\mathrm{mmHg})$} & $69.7 \pm 21.36$ & $65(56-74)$ & $1^{\circ}$ & {$[8,15]$} \\
\hline & & & $2^{\circ}$ & {$[15]$} \\
\hline \multirow[t]{2}{*}{$P_{\mathrm{aCO}_{2}}(\mathrm{mmHg})$} & $34.1 \pm 4.7$ & $32(28-84)$ & $1^{\circ}$ & {$[10,15]$} \\
\hline & & & $2^{\circ}$ & [15] \\
\hline \multirow[t]{2}{*}{$P_{\mathrm{aO}_{2}} / F_{\mathrm{IO}_{2}}$ ratio $(\mathrm{mmHg})$} & $182 \pm 65.29$ & $249 \pm 111$ & $1^{\circ}$ & {$[7,9,10,15]$} \\
\hline & & & $2^{\circ}$ & [15] \\
\hline \multirow[t]{2}{*}{ Respiratory rate (breaths per min) } & $23 \pm 4.8$ & $28(22-33)$ & $1^{\circ}$ & {$[8,10,15]$} \\
\hline & & & $2^{\circ}$ & [15] \\
\hline \multirow[t]{2}{*}{ Saturation (\%) } & $94 \pm 2.78$ & $93(89-97)$ & $1^{\circ}$ & {$[8,15,18]$} \\
\hline & & & $2^{\circ}$ & [15] \\
\hline
\end{tabular}

Data expressed as mean \pm SD or median (interquartile range), unless otherwise stated. $P_{\mathrm{aO}_{2}}$ : arterial oxygen tension; $P_{\mathrm{acO}}$ : arterial carbon dioxide tension; $F_{\mathrm{IO}_{2}}$ : inspiratory oxygen fraction.

Additional presentations include a "crazy-paving pattern" and halo signs - consolidations surrounded by ground-glass opacities. Peripheral sub-pleural lesions [27] may be wedge shaped, similar to pulmonary infarcts [29], and these resemble the initial lesions found during progressive experimental ventilator-induced lung injury (VILI) in mid-sized animal models [30]. It is tempting, therefore, to hypothesise that this radiological picture may reflect initial lesions due to patient self-inflicted lung injury
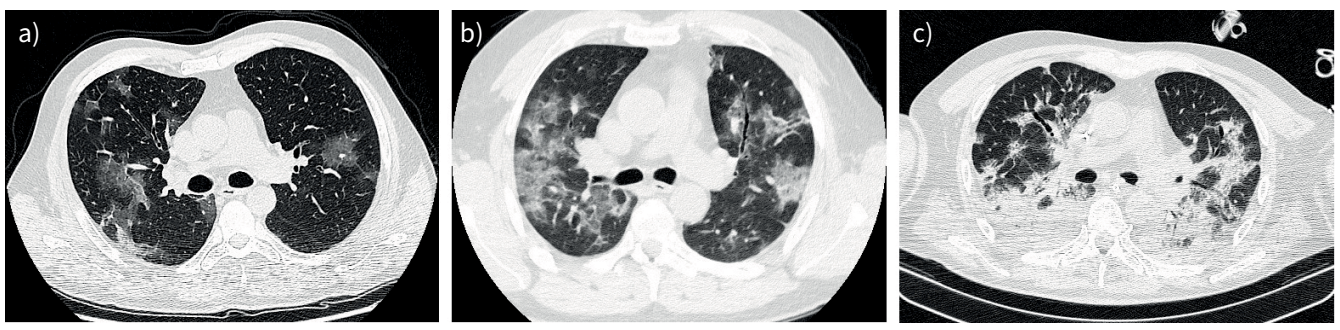

FIGURE 2 COVID-19 representative computed tomography scans. a) Emergency department: Lung weight $=1197.5 \mathrm{~g} ;$ Gas volume $=3937.6 \mathrm{~mL}$; Fraction of non-aerated tissue $=0.054 ; \quad P_{\mathrm{aO}_{2}} / F_{\mathrm{IO}_{2}} \quad$ ratio=146. b) High-dependency unit: Lung weight $=1088.6 \mathrm{~g}$; Gas volume $=1569.9 \mathrm{~mL}$; Fraction of non-aerated tissue $=0.168$; $P_{\mathrm{aO}_{2}} / F_{\mathrm{IO}_{2}}$ ratio=210. c) Intensive care unit: Lung weight=1399.2 g; Gas volume $=1257.5 \mathrm{~mL}$; Fraction of non-aerated tissue $=0.389 ; P_{\mathrm{aO}_{2}} / F_{\mathrm{IO}_{2}}$ ratio=112. $F_{\mathrm{IO}_{2}}$ : inspiratory oxygen fraction; $P_{\mathrm{aO}_{2}}$ : arterial oxygen tension. 
(P-SILI). Indeed, P-SILI may occur following abnormally high inspiratory effort which persists over time. In fact, COVID-19 patients experience increased respiratory drive and tidal volumes for several days prior to presenting at hospital.

The quantitative analysis of the CT scan at this stage of the disease shows only a modest increase in lung weight (10-20\% above normal) with a non-aerated tissue fraction of about $10 \%$ and gas volume within normal limits or only slightly reduced. Not surprisingly, respiratory system compliance is often near normal, given that this mechanical parameter reflects the amount of pulmonary gas volume [31]. Consistent with these findings is the low recruitability (or potential for lung recruitment, assessed either by CT scan or by single breath methods) found in patients who have been intubated in these early stages of the disease [32].

\section{Remarks}

Some remarks on gas exchange and treatment are needed at this stage.

Remarks on gas exchange

To fully account for the variability in gas exchange, a simultaneous assessment of ventilation and perfusion should ideally be performed. Unfortunately, the main variable employed clinically to assess gas exchange is the $P_{\mathrm{aO}_{2}} / F_{\mathrm{IO}_{2}}$ ratio, or oxygen saturation $\left(S_{\mathrm{pO}_{2}}\right) / F_{\mathrm{IO}_{2}}$ ratio - despite their recognised physiological limitations and susceptibility to confounders (e.g. $F_{\mathrm{IO}_{2}}$, airway pressure, haemodynamics etc.) $[33,34]$. At this stage of the disease, the clinical hallmark is the dissociation between hypoxaemia and the triad of CT scan pathoanatomy described above, modest dyspnoea and presence of "flexible lungs". The absence of dyspnoea, a subjective sensation, beyond an abnormal neuro-vegetative status may be explained by the preserved and near-normal respiratory system compliance, associated with an increased respiratory drive [26]. Indeed, if the respiratory system can generate tidal volumes the brain expects for a given respiratory effort, the compensatory response to the initial hypoxaemia is an increase in the minute ventilation (tidal volume first, then respiratory rate), hypocapnia, and minimal dyspnoea [35, 36]. Hypoxaemia, in severe respiratory failure of the usual aetiologies, commonly originates from a "true" shunt, i.e. the fraction of cardiac output which flows through the lungs without contacting alveolar gases (consolidated lung regions, venous-arterial anastomosis, intracardiac shunt). Hypoxaemia, however, may also occur because of a mismatch between regional ventilation and local perfusion [37]. Both mechanisms are included in RILEY's model, and regarded as venous admixture, which includes true shunt and ventilation/perfusion $\left(V^{\prime}{ }_{\mathrm{A}} / Q^{\prime}\right)$ maldistribution [38]. In COVID-19 the venous admixture ranges from $30 \%$ to $70 \%$ [39].

What evidence do we have available for addressing the mechanisms of impaired gas exchange at this stage of disease? The modest increase in lung weight and non-aerated tissue fraction, together with a high gas volume, exclude compression-atelectasis and the right-to-left shunt - typical of acute respiratory distress syndrome (ARDS) - as the primary cause of respiratory failure [31]. Extensive intracardiac shunting is also an unlikely explanation and is not in keeping with the natural history of the disease. The remaining possible mechanism, therefore, is a $V_{\mathrm{A}}^{\prime} / Q^{\prime}$ maldistribution. We hypothesised impaired control of lung perfusion and lack of appropriate hypoxic vasoconstriction as a primary mechanism of hypoxaemia [39, 40], as discussed in detail in the models presented by Herrmann et al. [41] and Busana et al. [42], who modelled hypoxaemia in patients with COVID-19 taking into account true shunt as well as $V^{\prime}{ }_{A} / Q^{\prime}$ maldistribution. Additional factors may account for the observed severe hypoxaemia in absence of true shunt: paradoxical hyperperfusion of poorly ventilated areas [43], hypoperfusion [43] and neo-vascularisation [44] with dysfunctional vessels generated by hypoxic tissue milieu. In summary, several physiological alterations seem to distinguish COVID-19 from other forms of respiratory failure having similar gas exchange impairment and indicate the primary role of altered lung perfusion in the pathogenesis of hypoxaemia.

\section{Remarks on treatment}

Treatment should be guided by an understanding of the pathophysiology. The general and understandable reaction during the first COVID-19 wave was to aggressively attempt to reverse hypoxaemia, given the large number of patients involved. Indiscriminate use of oxygen and a complete package of ventilatory support, mask continuous positive airways pressure (CPAP), helmet CPAP, high-flow nasal cannulas (HFNC) and noninvasive ventilation (NIV) were applied [45]. Given the underlying pathophysiology, a critical question is whether hypoxaemia per se justifies this therapeutic response, one based on prior ARDS literature and pathophysiology. Although the $P_{\mathrm{aO}_{2}} / F_{\mathrm{IO}_{2}}$ ratio is certainly in the range of severe ARDS $\left(P_{\mathrm{aO}_{2}} / F_{\mathrm{IO}_{2}}<100 \mathrm{mmHg}\right.$, and characterised by bilateral infiltrates and a noncardiac origin), the pathophysiology and early stage clinical pictures are impressively different: the ARDS "baby lung" [46] is substituted in C-ARDS (COVID-19 acute respiratory distress syndrome) by a lung of "adult" size [47]. 
This difference is further supported by the fact that the patient does not generally manifest problems of ventilation adequacy. A saturation between $85 \%$ and $90 \%$, with appropriate haemodynamics, is tolerable during spontaneous breathing. It is difficult within this framework to understand why recommendations and guidelines for the respiratory management of COVID-19 have proposed the adoption of standard ARDS treatment, i.e. simply follow the rules for severe ARDS [48-50]. The differences in the mechanisms and the best treatment approaches remain hotly debated questions.

It may be useful to distinguish the respiratory treatment approach taken during the first pandemic wave from that applied in the second one which benefited from the clinical experience and emerging scientific evidence and clinical trials. Indeed, if different, one possible question is whether new factors (virus mutations or changes in early/pre-hospital therapy) during the second phase could have changed the pathophysiology and, consequently, would dictate a change in the respiratory support. In fact, during the second wave, many patients were inappropriately (according to the guidelines) treated at home or in medical wards with steroids, anticoagulants and antivirals [51]. The results indicate that, on average, the clinical presentation to the ICU somehow became more severe [6]. In particular, dyspnoea was more frequently reported, along with an unusually high incidence of barotrauma, primarily pneumomediastiunum, pneumothorax and local blebs, cysts etc. [5]. Consequently, the respiratory approach, in terms of applied pressures, became somewhat less aggressive, even though COVID-19 was still largely managed following the strategies employed in the classical forms of ARDS [52].

\section{In the HDU}

During a pandemic, the significant strain on the healthcare system often means that the flow of patients from the emergency department to the HDU is more contingent on the availability of healthcare resources (staff and critical care beds) rather than guided by strictly objective clinical indications [53]. Resource constraints, therefore, often generate delays in the transfer of the patient to the most suitable site-of-care, and such delays increase the risk of dismal outcomes [54-56]. What we describe below pertains to "ideal conditions" in which bed availability in HDU is unrestricted.

\section{Clinical presentation}

The most common criterion for admission to the HDU is the severity of hypoxaemia, based on the $P_{\mathrm{aO}} /$ $F_{\mathrm{IO}_{2}}$ ratio and categorised using the decade-long definition of mild, moderate and severe acute respiratory failure $[57,58]$. At this stage, however, the patient may experience progressive worsening of respiratory distress, characterised by increased infiltrates on CT scan (figure 2b), deterioration of gas exchange, increased respiratory rate and increased respiratory drive (neural respiratory output). Heightened effort (respiratory muscle activity) generates dyspnoea or air hunger [59], i.e. the unpleasant subjective sensation of difficulty in breathing.

\section{Gas exchange}

The suggested respiratory support administered to these patients, ranges, in order of "invasiveness", from HFNC to mask or helmet CPAP and NIV, either in supine position or with the awake prone position [60, 61]. Additional pharmacological treatments active on pulmonary circulation (e.g. inhaled pulmonary vasodilators and almitrine) have been also reported [62, 63]. Their use, however, would benefit from preliminary assessment of pulmonary blood flow and pulmonary artery pressure.

\section{Prone positioning}

The use of the prone position in awake patients with early COVID-19 has gained increasing popularity and wide adoption. A "positive response" to prone position is usually defined as an increase in $P_{\mathrm{aO}_{2}}$ or $S_{\mathrm{pO}_{2}}$ above a certain threshold fraction compared with the supine position (usually $20 \%$ of $P_{\mathrm{aO}_{2}}$ or $\mathrm{P} / \mathrm{F}$ ratio), while keeping the airway pressure constant. The available data show that the proportion of "responders" ranges from $25 \%$ up to $75 \%[64,65]$. A positive response unfortunately may not change the natural progression of the disease and does not avert orotracheal intubation [66]. Although these data are informative at population level, such reports do not delineate the physiological mechanisms underlying the individual's response, nor explain the associated clinical features (disease duration or radiology). The effects of prone positioning on oxygenation, however, are short lasting and the improvement of oxygenation are often rapidly lost after resuming supine position. Decreased work of breathing has also been described as a benefit from this manoeuvre; however, the assessment is generally qualitative and subjective (comfort scale) or semi-quantitative [67], rather than quantitative and objective e.g. via oesophageal pressure measurements, diaphragm movement or electrical activity of the diaphragm [68-70]. 
High-flow nasal cannula

HFNC is currently the most recommended initial treatment for patients at this stage, due to its easy application and delivery, comfort, and provision of low PEEP (positive end-expiratory pressure) (2-5 $\mathrm{cmH}_{2} \mathrm{O}$, depending on the flow delivered) which does not induce alveolar over-distention [71, 72]. Another obvious advantage of HFNC is its ability to deliver gas flows that match the patient's mean inspiratory flow generated with high respiratory drive, therefore making it possible to supply oxygen at the set $F_{\mathrm{IO}_{2}}$ [73]. The additional advantages of dead space washout, air warming and humidification can reduce airway resistance and further decrease respiratory effort [74]. It is important to note, though, that the use of HFNC during the pandemic has been highly variable and influenced by three main factors: 1) inconsistent advice from different societies and guidelines, some of which discouraged the use of HFNC; 2) concerns regarding the high oxygen demand of these devices, potentially leading to exhaustion of the hospital's supply of oxygen; and 3) risk of viral spreading. Our opinion, however, is that HFNC is a valuable approach to these patients, provided it can achieve a reduction in inspiratory effort.

\section{Continuous positive airways pressure}

In patients with more severe oxygenation deficits - particularly in the presence of worsening lung oedema or atelectasis - higher airway pressures can be provided using CPAP devices using different interfaces. The use CPAP via helmet has been highly variable among different countries (e.g. the helmet is extremely popular in Italy [75], but almost ignored in the United States). CPAP is usually delivered at pressure levels between 5 and $15 \mathrm{cmH}_{2} \mathrm{O}$ [75]. During the first pandemic wave, the median level of CPAP reported was as high as $14(12-16) \mathrm{cmH}_{2} \mathrm{O}$ [13]. Over the course of the pandemic - especially in the second wave - observational data indicate that CPAP pressure levels have substantially decreased, while its use increased [16].

\section{Noninvasive ventilation}

NIV provides additional inspiratory support and is primarily indicated when hypoxaemia is associated with modest worsening of ventilation requirements and the need to increase alveolar ventilation or reduce the workload of the respiratory muscles. Available data suggest that, once again, the indication for the use of NIV has been worsening hypoxaemia rather than any measure of respiratory effort or ventilator insufficiency [76]. A high inspiratory effort represents, not only as an indication to start NIV but also (and perhaps more importantly) to detect NIV failure and need to escalate treatment to invasive ventilation [77].

\section{Remarks}

Noninvasive respiratory support

The noninvasive techniques we discussed above are sufficient, in most patients, to maintain adequate gas exchange. At this stage, improvement occurs in many of them. Particular attention, however, should be devoted to the patients in whom NIV is unable to reduce the excessive inspiratory effort. Indeed, this condition of persistent increased lung stress and strain, may be associated with the development or worsening of P-SILI.

\section{Indications for mechanical ventilation}

Unfortunately, hypoxaemia remains the only parameter used to assess patient's respiratory status, and the correction of impaired oxygenation is the target which best satisfies the clinician. It is seldom discussed that improved oxygenation per se is not synonymous with better survival. In fact, data show that better survival could be associated with worse oxygenation when lung protective measures are instituted [78]. The predominant focus on oxygenation distracts from important additional assessments and, as a result, several important variables are left unmeasured, under-evaluated or completely ignored. These include changes in $P_{\mathrm{aCO}}$, respiratory rate, spontaneous tidal volume or stress and strain. Indeed, a key remark for this period concerns the indications for mechanical ventilation, a decision for which a large amount of literature is available but clear and objective criteria are lacking. It must be noted that most reports adopt an epidemiologic description of "early" versus "late", without any attempt to justify or elucidate physiologic mechanisms [79-89] (table 2). The designation of "early or late” is usually based on an arbitrary criterion based on the time from hospital/ICU admission to intubation rather than on the clinical characteristics that would identify an "early" or "late" disease. This approach is further confounded by the lack of data that match patients cared for outside the ICU with the same disease severity as ones admitted to ICU. The lack of a true "denominator" and huge variations in resources and practice environments make it difficult to describe and compare in detail the extensive literature available that lacks appropriate mechanistic data [90]. The role and timing of invasive mechanical ventilation at this stage is the crucial but controversial issue. The two main issues seem to be: 1) the uncertain timing and indication for invasive mechanical ventilation; and 2) the dramatic deterioration of respiratory function (primarily gas exchange and mechanics) often clinically observed when switching from NIV to invasive mechanical ventilation. 


\begin{tabular}{|c|c|c|c|c|c|}
\hline Author & $\begin{array}{l}\text { Patients } \\
\text { enrolled }\end{array}$ & $\begin{array}{c}\text { Early intubation } \\
\mathrm{n}(\%)\end{array}$ & $\begin{array}{c}\text { Deceased } \\
\text { n (\%) }\end{array}$ & $\begin{array}{c}\text { Late intubation } \\
\mathrm{n}(\%)\end{array}$ & $\begin{array}{c}\text { Deceased } \\
\text { n (\%) }\end{array}$ \\
\hline Zuccon [79] & 54 & $25(46.3)$ & $9(36)$ & $23(42.6)$ & $12(52.2)$ \\
\hline LeE $[80]$ & 47 & $23(48.9)$ & $13(56.5)$ & $16(34.0)$ & $7(43.8)$ \\
\hline KARAGIANNIDIS [81] & 10021 & $1318(13.2)$ & $696(52.8)$ & $141(1.4)$ & $70(49.6)$ \\
\hline GrASSELLI [82] & 3988 & $2929(73.4)$ & $1514(51.7)$ & $151(3.8)$ & NA \\
\hline МАTTA [83] & 111 & 76 (68.5) & 54 (71.1) & 35 (31.5) & $20(57.1)$ \\
\hline HeRnandez-Romieu [84] & 231 & $132(57.1)$ & $47(35.6)$ & $42(18.2)$ & $16(38.1)$ \\
\hline MelLado-Artigas [85] & 122 & $61(50)$ & $13(21.3)$ & $23(18.9)$ & $6(26.1)$ \\
\hline PANDYA $[86]$ & 75 & $37(49.3)$ & $20(54.1)$ & $38(50.7)$ & $18(47.4)$ \\
\hline RoEDL [87] & 223 & 66 (29.6) & $26(39.4)$ & 46 (20.6) & $20(43.5)$ \\
\hline BAVISHI [88] & 54 & $30(55.6)$ & $2(6.7)$ & $24(44.4)$ & $7(29.2)$ \\
\hline COVID-ICU GRoup [89] & 4244 & $2635(62.1)$ & $957(36.3)$ & 741 (17.5) & $244(32.9)$ \\
\hline Total & 4978 & $7332(38.2)$ & $3351(45.7)$ & $1280(6.7)$ & $420(37.2)$ \\
\hline
\end{tabular}

Despite the attempts to define the intubation criteria, as in randomised trials [34], current expert opinion appears to be that intubation should simply be based on clinical judgement [91]. We recently found that when the decision was left to the attending physician, the "need for mechanical ventilation" was determined by a mixture of criteria relating to deterioration in gas exchange and increased respiratory drive, often associated with cognitive alteration (anxiety, confusion, delirium) or extra-respiratory organ failure. In some COVID-19 patients the problem is not an insufficient ventilation but, on the contrary, the spontaneous and uncontrolled hyperventilation, for which mechanical ventilation represents a means to protect the lungs against P-SILI. Therefore, a possible indication for intubation may not be the distress per se (as this can be absent or tolerable), but the persistence of uncontrolled inspiratory effort and risk of P-SILI, the hazard from which could be primarily confirmed by objective measures, e.g. oesophageal pressure swings, diaphragm displacement, central venous pressure swings or high tidal volumes during NIV, reportedly associated with its failure [92].

\section{In the ICU}

\section{Clinical presentation}

Mechanical ventilation, that for sake of clarity we may consider as the start of the intensive care period, it is often associated with a remarkable deterioration of the respiratory system. Indeed, often the lung gas volume and respiratory system compliance decreases, oxygenation worsens and $P_{\mathrm{aCO}}$ may increase. Most of the observed events are caused by sedation and paralysis, which lead to a loss of muscular (skeletal and diaphragmatic) tone, the under-appreciation of the true driving pressure exerted during spontaneous breathing [77] and therefore hypoventilation at lower tidal volumes and with more protective driving pressures. These changes induce formation of atelectasis with consequent loss of lung gas volume. Concurrent with these well-known phenomena, it is possible that additional fluid loads during this phase may be, if not a determinant, at least a contributing factor to increased lung oedema and deterioration in lung function. We described this stage at its extreme, as Type $\mathrm{H}$, characterised by higher elastance, lung weight, right-to-left shunt and recruitability [39]. The latter is known to progressively increase with worsening of disease severity.

\section{Gas exchange}

During this phase - although the oxygenation can be partially corrected - a progressive rise of $P_{\mathrm{aCO}_{2}}$ and dead space becomes evident, as widely described, in association with structural changes of lung parenchyma [93, 94]. Responses to recruitment manoeuvres, higher PEEP and prone position progressively vanish. Indeed, oxygenation in a fraction of patients close to $50 \%$ may decreased instead of increasing. This phenomenon is consistent with a progressive shift from oedema to the fibrotic status [95].

\section{Imaging}

As shown in figure 2c, the CT scan image is remarkably changed compared with those of the initial and intermediate phases, and the overall picture is comparable with the ARDS pattern. Note, however, that more than a typical ARDS, this picture resembles ARDS not resolving after 2 or 3 weeks of treatment, which, unfortunately, is far less frequently encountered in our experience. The primary alteration occurring 
in these patients is likely to be the progressive shift from oedema and atelectasis to organising pneumonia, with fibrotic and structural changes of the lung [96]. Such findings are consistent with the pathophysiological features observed in the later stages of typical ARDS [94]. We may also wonder whether some of the positive benefits associated with the administration of dexamethasone in the late stages simply reflect remodelling of the fibrotic reaction [97], or the resolution of organising pneumonia. The reports of several patients with the appearance of CT scan features compatible with fibrosis but with near-normalisation of lung radiology should caution against early prognostication of irreversibility and established fibrosis [98]. This, in turn, has implications in terms of resources, duration of organ support or suitability for lung transplant.

\section{Treatment}

In the intensive care phase, the principles of treatment should not differ significantly from the one recommended for the management of ARDS. However, great attention should be paid to the setting of PEEP, as the prerequisites for PEEP effectiveness (i.e. lung oedema or atelectasis) are present only in the intermediate phases of COVID-19 disease, and are less prevalent in the very early or very late phases. Ideally, a careful monitoring of the hemodynamic and the respiratory system mechanics could guide the most appropriate ventilator treatment in a given patient.

\section{Extracorporeal support}

Extracorporeal membrane oxygenation (ECMO) has been used in around 3\% of patients with severe COVID-19. Although often life-saving, ECMO represents a form of support that buys time to allow healing and recovery - sometimes after several weeks - or to determine the potential reversibility of the lung injury. The current survival in patients that receive ECMOis 51\% [99]. However, several factors play an important role, including pre-existing comorbidities, type of ECMO support (veno-venous versus veno-arterial or hybrid) [100, 101] and, importantly, the case volume [101, 102] and experience of the ECMO centre. Ultimately, the determination of irreversibility and consideration of withdrawal of organ support or consideration of lung transplant, despite some initial encouraging results [101, 103], is extremely difficult particularly during pandemic times, and requires longer term data.

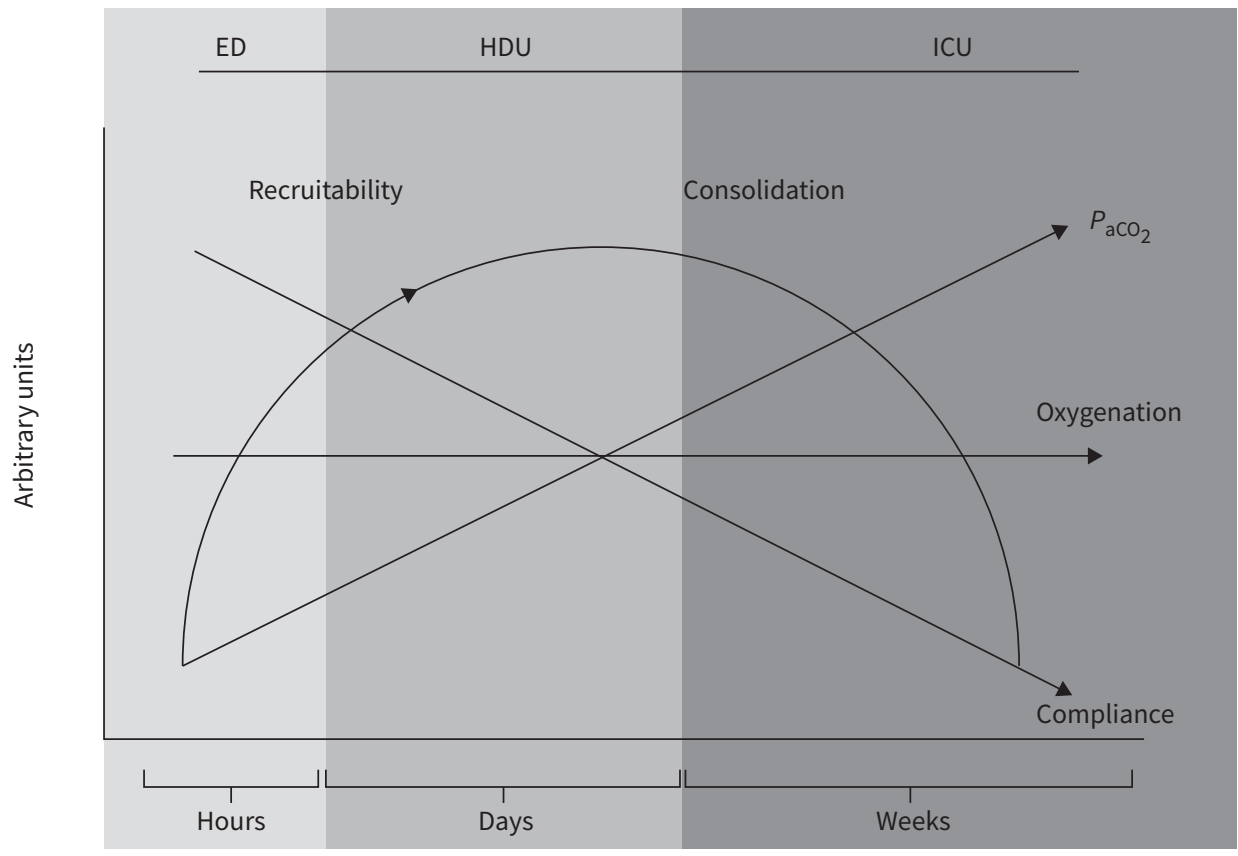

FIGURE 3 Summary of COVID-19 pathophysiology time course of patients who fail to improve. Atelectasis/ recruitability progressively increase during the disease course until a later phase, characterised by fibrosis development. These anatomical changes are associated with a progressive decrease of respiratory system compliance, same or higher ventilation and a decreased $P_{\mathrm{acO}}$. Note that oxygenation does not change remarkably during the disease course, although, the mechanisms of hypoxaemia are likely to shift from $V^{\prime}{ }_{A} / Q^{\prime}$ misdistribution to true shunt. ED: emergency department; HDU: high-dependency unit; ICU: intensive care unit; $P_{\mathrm{aco}}$ : arterial carbon dioxide tension; $V^{\prime}{ }_{\mathrm{A}} / Q^{\prime}$ : ventilation/perfusion ratio. 
Conclusions and final remarks

In figure 3 we summarise the time course of the evolution of COVID-19 we have observed, highlighting possible controversies. Let's first state that COVID-19 disease is not at all a "heterogeneous disease" as we do not know of, nor have we experienced, of any other condition in which thousands of the patients were so similar at a given and specific phase of the disease. On the contrary, heterogeneity is generated by the inclusion of patients with the same disease but at different stages of evolution along a largely homogeneous disease trajectory [104]. Having said that, the pathoanatomy of unresolving disease progresses from an inflamed non-oedematous, non-atelectatic lung to one having an increased oedema and atelectasis phase, eventually to shift toward a fibrotic lung structure in the late phase. These pathoanatomical changes are associated with progressive changes of gas volumes and respiratory mechanics. Obviously, if time is not taken in consideration, reports about compliance values of these patients and other characteristics appear conflicting. The $P_{\mathrm{aCO}}$ and the response to common manoeuvres for recruitment such as raising PEEP and prone positioning change with time; it is also very likely that the mechanisms underlying the oxygenation impairment change with time: from primary $V^{\prime}{ }_{\mathrm{A}} / Q^{\prime}$ maldistribution, to primary true shunt alterations when oedema increases and COVID-19 disease progresses. It is possible that further improvement in respiratory treatment - which are primarily based on avoidance of further complications (e.g. super-infections, sepsis, barotrauma etc.) instead of inventing miracle solutions - would require a better understating of the underlying mechanisms. These in turn, need more frequent and focused attention to respiratory monitoring as a guide to optimal and timely treatment.

Provenance: Commissioned article, peer reviewed.

Acknowledgements: We thank Massimo Fileni (Italy) for the precious support he provided to the study group.

Author contributions: Conception and design: S. Gattarello, I. Steinberg, M. Busana and L. Gattinoni. Data acquisition for tables and figures: P. Palermo, S. Lazzari and F. Romitti. Analysis and interpretation: P. Palermo, S. Lazzari, F. Romitti, S. Gattarello, I. Steinberg and M. Busana. Drafting the manuscript for important intellectual content: D. Chiumello, K. Meissner, M. Quintel, J.J. Marini, L. Camporota and L. Gattinoni.

Conflicts of interest: L. Gattinoni reports consultancy fee from General Electrics and SIDAM. He also received lecture fees from Estor and Dimar. S. Gattarello has nothing to disclose. I. Steinberg has nothing to disclose. M. Busana has nothing to disclose. P. Palermo has nothing to disclose. S. Lazzari has nothing to disclose. F. Romitti has nothing to disclose. M. Quintel has nothing to disclose. K. Meissner has nothing to disclose. J.J. Marini has nothing to disclose. D. Chiumello has nothing to disclose. L. Camporota has nothing to disclose.

Support statement: The support for this work was provided from departmental sources and from two unrestricted grants for research in respiratory medicine, apportioned by Sartorius AG (Otto-Brenner-Straße 20, 37079, Göttingen, Germany). Funding information for this article has been deposited with the Crossref Funder Registry.

\section{References}

1 Zhu N, Zhang D, Wang W, et al. A novel coronavirus from patients with pneumonia in China, 2019. N Engl J Med 2020; 382: 727-733.

2 WHO. WHO Coronavirus (COVID-19) Dashboard. http://covid19.who.int Date last accessed: June 17, 2021.

3 Remap-Cap. REMAP-CAP. www.remapcap.org Date last accessed: June 15, 2021.

4 Johns Hopkins University of Medicine. Coronavirus Resource Centre. https://coronavirus.jhu.edu Date last accessed: June 15, 2021.

5 Martinelli AW, Ingle T, Newman J, et al. COVID-19 and pneumothorax: a multicentre retrospective case series. Eur Respir J 2020; 56: 2002697.

6 Iftimie S, Lopez-Azcona AF, Vallverdu I, et al. First and second waves of coronavirus disease-19: a comparative study in hospitalized patients in Reus, Spain. PLOS ONE 2021; 16: e0248029.

7 Soriano V, Ganado-Pinilla P, Sanchez-Santos M, et al. Main differences between the first and second waves of COVID-19 in Madrid, Spain. Int J Infect Dis 2021; 105: 374-376.

8 Jalali SF, Ghassemzadeh M, Mouodi S, et al. Epidemiologic comparison of the first and second waves of coronavirus disease in Babol, North of Iran. Caspian J Intern Med 2020; 11: Suppl. 1, 544-550.

9 Thibeault C, Muhlemann B, Helbig ET, et al. Clinical and virological characteristics of hospitalised COVID-19 patients in a German tertiary care centre during the first wave of the SARS-CoV-2 pandemic: a prospective observational study. Infection 2021; 49: 703-714.

10 Giacomelli A, Ridolfo AL, Milazzo L, et al. 30-day mortality in patients hospitalized with COVID-19 during the first wave of the Italian epidemic: a prospective cohort study. Pharmacol Res 2020; 158: 104931. 
Taboada M, Gonzalez M, Alvarez A, et al. First, second and third wave of COVID-19. What have we changed in the ICU management of these patients? J Infect 2021; 82: e14-e15.

Huang C, Wang Y, Li X, et al. Clinical features of patients infected with 2019 novel coronavirus in Wuhan, China. Lancet 2020; 395: 497-506.

Grasselli G, Zangrillo A, Zanella A, et al. Baseline characteristics and outcomes of 1591 patients infected with SARS-CoV-2 admitted to ICUs of the Lombardy Region, Italy. JAMA 2020; 323: 1574-1581.

Santus P, Radovanovic D, Saderi L, et al. Severity of respiratory failure at admission and in-hospital mortality in patients with COVID-19: a prospective observational multicentre study. BMJ Open 2020; 10: e043651.

Singh P, Jain P, Deewan H. Awake prone positioning in COVID-19 patients. Indian J Crit Care Med 2020; 24: 914-918.

Radovanovic D, Pini S, Franceschi E, et al. Characteristics and outcomes in hospitalized COVID-19 patients during the first 28 days of the spring and autumn pandemic waves in Milan: an observational prospective study. Respir Med 2021; 178: 106323.

Domingo P, Pomar V, Mur I, et al. Not all COVID-19 pandemic waves are alike. Clin Microbiol Infect 2021; 27: 1040.e7-1040.e10.

Lampl BMJ, Salzberger B. Changing epidemiology of COVID-19. GMS Hyg Infect Control 2020; 15: Doc27.

Avdeev SN, Yaroshetskiy Al, Tsareva NA, et al. Noninvasive ventilation for acute hypoxemic respiratory failure in patients with COVID-19. Am J Emerg Med 2021; 39: 154-157.

Mocanu A, Noja GG, Istodor AV, et al. Individual characteristics as prognostic factors of the evolution of hospitalized COVID-19 Romanian patients: a comparative observational study between the first and second waves based on gaussian graphical models and structural equation modeling. J Clin Med 2021; 10: 1958.

Mollinedo-Gajate I, Villar-Alvarez F, Zambrano-Chacon MLA, et al. First and second waves of coronavirus disease 2019 in Madrid, Spain: clinical characteristics and hematological risk factors associated with critical/ fatal illness. Crit Care Explor 2021; 3: e0346.

Sacerdote C, Castiglione A, Pagano E, et al. Clinical and epidemiological characteristics associated with pneumonia at disease onset in patients admitted for COVID-19 to the emergency department of a large hospital in Piedmont (North-Western Italy). Epidemiol Prev 2020; 44: Suppl. 2, 216-225.

Bulfamante G, Bocci T, Falleni M, et al. Brainstem neuropathology in two cases of COVID-19: SARS-CoV-2 trafficking between brain and lung. J Neurol 2021; in press [https://doi.org/10.1007/s00415-021-10604-8]. Anestesiol 2021; 87: 325-333.

Wang D, Hu B, Hu C, et al. Clinical characteristics of 138 hospitalized patients with 2019 novel coronavirus-infected pneumonia in Wuhan, China. JAMA 2020; 323: 1061-1069.

Simonson TS, Baker TL, Banzett RB, et al. Silent hypoxaemia in COVID-19 patients. J Physiol 2021; 599: 1057-1065.

Chung M, Bernheim A, Mei X, et al. CT Imaging features of 2019 novel coronavirus (2019-nCoV). Radiology 2020; 295: 202-207.

Kwee TC, Kwee RM. Chest CT in COVID-19: what the radiologist needs to know. Radiographics 2020; 40: 1848-1865.

Duzgun SA, Durhan G, Demirkazik FB, et al. COVID-19 pneumonia: the great radiological mimicker. Insights Imaging 2020; 11: 118.

Cressoni M, Gotti M, Chiurazzi C, et al. Mechanical power and development of ventilator-induced lung injury. Anesthesiology 2016; 124: 1100-1108.

Chiumello D, Busana M, Coppola S, et al. Physiological and quantitative CT-scan characterization of COVID-19 and typical ARDS: a matched cohort study. Intensive Care Med 2020; 46: 2187-2196.

Pan C, Chen L, Lu C, et al. Lung recruitability in COVID-19-associated acute respiratory distress syndrome: a single-center observational study. Am J Respir Crit Care Med 2020; 201: 1294-1297.

Gattinoni L, Vassalli F, Romitti F. Benefits and risks of the P/F approach. Intensive Care Medicine 2018; 44: 2245-2247.

Hakim R, Watanabe-Tejada L, Sukhal S, et al. Acute respiratory failure in randomized trials of noninvasive respiratory support: a systematic review of definitions, patient characteristics, and criteria for intubation. J Crit Care 2020; 57: 141-147.

Banzett RB, Lansing RW, Binks AP. Air hunger: a primal sensation and a primary element of dyspnea. Compr Physiol 2021; 11: 1449-1483.

Vaporidi K, Akoumianaki E, Telias I, et al. Respiratory drive in critically ill patients. pathophysiology and clinical implications. Am J Respir Crit Care Med 2020; 201: 20-32.

Pesenti A, Riboni A, Marcolin R, et al. Venous admixture (Qva/Q) and true shunt (Qs/Qt) in ARF patients: effects of PEEP at constant FIO2. Intensive Care Med 1983: 9: 307-311.

Riley RL, Cournand A. Ideal alveolar air and the analysis of ventilation-perfusion relationships in the lungs. J Appl Physiol 1949; 1: 825-847. 
Gattinoni L, Chiumello D, Caironi P, et al. COVID-19 pneumonia: different respiratory treatment for different phenotypes. Intensive Care Med 2020; 46: 1099-1102.

Marini JJ, Gattinoni L. Management of COVID-19 respiratory distress. JAMA 2020; 323: 2329-2330. hypoxemia. Nat Commun 2020; 11: 4883.

Busana M, Giosa L, Cressoni M, et al. The impact of ventilation-perfusion inequality in COVID-19: a computational model. J Appl Physiol 2021; 130: 865-876.

Lang M, Som A, Mendoza DP, et al. Hypoxaemia related to COVID-19: vascular and perfusion abnormalities on dual-energy CT. Lancet Infect Dis 2020; 20: 1365-1366.

Ackermann M, Verleden SE, Kuehnel M, et al. Pulmonary vascular endothelialitis, thrombosis, and angiogenesis in Covid-19. N Engl J Med 2020; 383: 120-128.

Gorman E, Connolly B, Couper K, et al. Non-invasive respiratory support strategies in COVID-19. Lancet Respir Med 2021; 9: 553-556.

Gattinoni L, Pesenti A. The concept of "baby lung". Intensive Care Med 2005; 31: 776-784.

Gattinoni L, Chiumello D, Rossi S. COVID-19 pneumonia: ARDS or not? Crit Care 2020; 24: 154.

Alhazzani W, Moller MH, Arabi YM, et al. Surviving Sepsis Campaign: guidelines on the management of critically ill adults with Coronavirus Disease 2019 (COVID-19). Intensive Care Med 2020; 46: 854-887.

National Institutes of Health. Coronavirus Disease 2019 (COVID-19) Treatment Guidelines. Bethesda, MD, National Institutes of Health (US); 2021.

Fan E, Beitler JR, Brochard L, et al. COVID-19-associated acute respiratory distress syndrome: is a different approach to management warranted? Lancet Respir Med 2020; 8: 816-821.

WHO. Clinical management of COVID-19: interim guidance, 27 May 2020. Geneva, World Health Organization; 2020. https://apps.who.int/iris/handle/10665/332196

Grasselli G, Cattaneo E, Florio G, et al. Mechanical ventilation parameters in critically ill COVID-19 patients: a scoping review. Crit Care 2021; 25: 115.

Li J, Huang DQ, Zou B, et al. Epidemiology of COVID-19: a systematic review and meta-analysis of clinical characteristics, risk factors, and outcomes. J Med Virol 2021; 93: 1449-1458.

Barrett K, Khan YA, Mac S, et al. Estimation of COVID-19-induced depletion of hospital resources in Ontario, Canada. CMAJ 2020; 192: E640-E646.

Remuzzi A, Remuzzi G. COVID-19 and Italy: what next? Lancet 2020; 395: 1225-1228.

Rommele C, Neidel T, Heins J, et al. [Bed capacity management in times of the COVID-19 pandemic: a simulation-based prognosis of normal and intensive care beds using the descriptive data of the University Hospital Augsburg]. Anaesthesist 2020; 69: 717-725.

Ranieri VM, Rubenfeld GD, Thompson BT, et al. Acute respiratory distress syndrome: the Berlin Definition. JAMA 2012; 307: 2526-2533.

Maiolo G, Collino F, Vasques F, et al. Reclassifying acute respiratory distress syndrome. Am J Respir Crit Care Med 2018; 197: 1586-1595.

Allali G, Marti C, Grosgurin O, et al. Dyspnea: the vanished warning symptom of COVID-19 pneumonia. J Med Virol 2020; 92: 2272-2273.

Sartini C, Tresoldi M, Scarpellini P, et al. Respiratory parameters in patients with COVID-19 after using noninvasive ventilation in the prone position outside the intensive care unit. JAMA 2020; 323: 2338-2340.

61 Coppo A, Bellani G, Winterton D, et al. Feasibility and physiological effects of prone positioning in non-intubated patients with acute respiratory failure due to COVID-19 (PRON-COVID): a prospective cohort study. Lancet Respir Med 2020; 8: 765-774.

Lotz C, Muellenbach RM, Meybohm P, et al. Effects of inhaled nitric oxide in COVID-19-induced ARDS - is it worthwhile? Acta Anaesthesiol Scand 2021; 65: 629-632.

Losser MR, Lapoix C, Delannoy M, et al. Almitrine as a non-ventilatory strategy to improve intrapulmonary shunt in COVID-19 patients. Anaesth Crit Care Pain Med 2020; 39: 467-469.

Elharrar X, Trigui Y, Dols AM, et al. Use of prone positioning in nonintubated patients with COVID-19 and hypoxemic acute respiratory failure. JAMA 2020; 323: 2336-2338.

Langer T, Brioni M, Guzzardella A, et al. Prone position in intubated, mechanically ventilated patients with COVID-19: a multi-centric study of more than 1000 patients. Crit Care 2021; 25: 128.

Ferrando C, Mellado-Artigas R, Gea A, et al. Awake prone positioning does not reduce the risk of intubation in COVID-19 treated with high-flow nasal oxygen therapy: a multicenter, adjusted cohort study. Crit Care 2020; 24: 597.

Apigo M, Schechtman J, Dhliwayo N, et al. Development of a work of breathing scale and monitoring need of intubation in COVID-19 pneumonia. Crit Care 2020; 24: 477.

Roesthuis L, van den Berg M, van der Hoeven $\mathrm{H}$. Non-invasive method to detect high respiratory effort and transpulmonary driving pressures in COVID-19 patients during mechanical ventilation. Ann Intensive Care 2021; 11: 26. 
Boussuges A, Gole Y, Blanc P. Diaphragmatic motion studied by m-mode ultrasonography: methods, reproducibility, and normal values. Chest 2009; 135: 391-400.

Barwing J, Pedroni C, Olgemoller $\mathrm{U}$, et al. Electrical activity of the diaphragm (EAdi) as a monitoring parameter in difficult weaning from respirator: a pilot study. Crit Care 2013; 17: R182.

Kolb M, Dinh-Xuan AT, Brochard L. Guideline-directed management of COVID-19: do's and don'ts. Eur Respir J 2021; 57: 2100753.

Ricard JD, Roca O, Lemiale V, et al. Use of nasal high flow oxygen during acute respiratory failure. Intensive Care Med 2020; 46: 2238-2247.

Rochwerg B, Einav S, Chaudhuri D, et al. The role for high flow nasal cannula as a respiratory support strategy in adults: a clinical practice guideline. Intensive Care Med 2020; 46: 2226-2237.

Mauri T, Wang YM, Dalla Corte F, et al. Nasal high flow: physiology, efficacy and safety in the acute care setting, a narrative review. Open Access Emerg Med 2019; 11: 109-120.

Grieco DL, Menga LS, Cesarano M, et al. Effect of helmet noninvasive ventilation vs high-flow nasal oxygen on days free of respiratory support in patients with covid-19 and moderate to severe hypoxemic respiratory failure: the HENIVOT randomized clinical trial. JAMA 2021; 325: 1731-1743.

Arulkumaran N, Brealey D, Howell D, et al. Use of non-invasive ventilation for patients with COVID-19: a cause for concern? Lancet Respir Med 2020; 8: e45.

Tonelli R, Fantini R, Tabbi L, et al. Early inspiratory effort assessment by esophageal manometry predicts noninvasive ventilation outcome in de novo respiratory failure. A Pilot Study. Am J Respir Crit Care Med 2020; 202: 558-567.

Acute Respiratory Distress Syndrome Network, Brower RG, Matthay MA, et al. Ventilation with lower tidal volumes as compared with traditional tidal volumes for acute lung injury and the acute respiratory distress syndrome. N Engl J Med 2000; 342: 1301-1308.

Zuccon W, Comassi P, Adriani L, et al. Intensive care for seriously ill patients affected by novel coronavirus SARS-CoV-2: experience of the Crema Hospital, Italy. Am J Emerg Med 2020: 45; 156-161.

Lee $\mathrm{YH}$, Choi KJ, Choi SH, et al. Clinical significance of timing of intubation in critically ill patients with COVID-19: a multi-center retrospective study. J Clin Med 2020; 9; 2847.

Karagiannidis C, Mostert C, Hentschker C, et al. Case characteristics, resource use, and outcomes of 10021 patients with COVID-19 admitted to 920 German hospitals: an observational study. Lancet Respir Med 2020; 8: 853-862.

Grasselli G, Greco M, Zanella A, et al. Risk factors associated with mortality among patients with COVID-19 in intensive care units in Lombardy, Italy. JAMA Intern Med 2020; 180: 1345-1355.

Matta A, Chaudhary S, Bryan Lo K, et al. Timing of intubation and its implications on outcomes in critically ill patients with coronavirus disease 2019 infection. Crit Care Explor 2020; 2: e0262.

Hernandez-Romieu AC, Adelman MW, Hockstein MA, et al. Timing of intubation and mortality among critically ill coronavirus disease 2019 patients: a single-center cohort study. Crit Care Med 2020; 48: e1045-e1053.

Mellado-Artigas R, Ferreyro BL, Angriman F, et al. High-flow nasal oxygen in patients with COVID-19associated acute respiratory failure. Crit Care 2021; 25: 58.

Pandya A, Kaur NA, Sacher D, et al. Ventilatory mechanics in early vs late intubation in a cohort of coronavirus disease 2019 patients with ARDS: a single center's experience. Chest 2021; 159: 653-656.

Roedl K, Jarczak D, Thasler L, et al. Mechanical ventilation and mortality among 223 critically ill patients with coronavirus disease 2019: a multicentric study in Germany. Aust Crit Care 2021; 34: 167-175.

Bavishi AA, Mylvaganam RJ, Agarwal R, et al. Timing of intubation in coronavirus disease 2019: a study of ventilator mechanics, imaging, findings, and outcomes. Crit Care Explor 2021; 3: e0415.

COVID-ICU Group on behalf of the REVA Network and the COVID-ICU Investigators. Clinical characteristics and day-90 outcomes of 4244 critically ill adults with COVID-19: a prospective cohort study. Intensive Care Med 2021; 47: 60-73.

Wunsch H. Mechanical ventilation in COVID-19: interpreting the current epidemiology. Am J Respir Crit Care Med 2020; 202: 1-4.

Tobin MJ. The criteria used to justify endotracheal intubation of patients with COVID-19 are worrisome. Can J Anaesth 2021; 68: 258-259.

Carteaux G, Millan-Guilarte T, De Prost N, et al. Failure of noninvasive ventilation for de novo acute hypoxemic respiratory failure: role of tidal volume. Crit Care Med 2016; 44: 282-290.

Nuckton TJ, Alonso JA, Kallet RH, et al. Pulmonary dead-space fraction as a risk factor for death in the acute respiratory distress syndrome. N Engl J Med 2002; 346: 1281-1286.

Gattinoni L, Bombino $\mathrm{M}$, Pelosi $\mathrm{P}$, et al. Lung structure and function in different stages of severe adult respiratory distress syndrome. JAMA 1994; 271: 1772-1779.

Smit MR, Beenen LFM, Valk CMA, et al. Assessment of lung reaeration at 2 levels of positive end-expiratory pressure in patients with early and late COVID-19-related acute respiratory distress syndrome. $J$ Thorac Imaging 2021; in press. 
Barisione E, Grillo F, Ball L, et al. Fibrotic progression and radiologic correlation in matched lung samples from COVID-19 post-mortems. Virchows Arch 2021; 478: 471-485.

97 Steinberg KP, Hudson LD, Goodman RB, et al. Efficacy and safety of corticosteroids for persistent acute respiratory distress syndrome. N Engl J Med 2006; 354: 1671-1684.

98 Rai DK, Sharma P, Kumar R. Post covid 19 pulmonary fibrosis. Is it real threat? Indian J Tuberc 2021; 68: 330-333.

99 ELSO. Full COVID-19 Registry Dashboard. www.elso.org/Registry/FullCOVID19RegistryDashboard.aspx Date last accessed: June 14, 2021.

100 Barbaro RP, MacLaren G, Boonstra PS, et al. Extracorporeal membrane oxygenation support in COVID-19: an international cohort study of the Extracorporeal Life Support Organization registry. Lancet 2020; 396: 1071-1078.

101 Lebreton G, Schmidt M, Ponnaiah M, et al. Extracorporeal membrane oxygenation network organisation and clinical outcomes during the COVID-19 pandemic in Greater Paris, France: a multicentre cohort study. Lancet Respir Med 2021; 9: 851-862.

102 Barbaro RP, Odetola FO, Kidwell KM, et al. Association of hospital-level volume of extracorporeal membrane oxygenation cases and mortality. Analysis of the extracorporeal life support organization registry. Am J Respir Crit Care Med 2015; 191: 894-901.

103 Bharat A, Machuca TN, Querrey M, et al. Early outcomes after lung transplantation for severe COVID-19: a series of the first consecutive cases from four countries. Lancet Respir Med 2021; 9: 487-497.

104 Marini JJ, Gattinoni L. Time course of evolving ventilator-induced lung injury: the "shrinking baby lung". Crit Care Med 2020; 48: 1203-1209. 